\title{
Higher Order Rotating Cavitation in an Inducer
}

\author{
Akira Fujii, Seiji Azuma, Yoshiki Yoshida, Yoshinobu Tsujimoto, \\ and Hironori Horiguchi \\ Osaka University, Engineering Science, Osaka, Japan
}

Satoshi Watanabe

Kyushu University, Faculty of Engineering, Fukuoka, Japan

In the present study, a higher order rotating cavitation predicted by the stability analysis was identified through the measurements of inlet pressure fluctuations and blade stress fluctuations. The propagation speed ratio of the higher order rotating cavitation is approximately 5 , and the amplitude of the blade stress fluctuation caused by this rotating cavitation is the same level as that by the conventional rotating cavitation. In addition, a higher order cavitation surge was observed at the transition point from the conventional to the higher order rotating cavitation.

Keywords Blade stress fluctuation, Cavitation, Cavitaion surge, Inducer, Rotating cavitation

For the rocket engine turbopump, inducer is often placed upstream of the centrifugal impeller to improve the cavitation performance. However, it often suffers from the cavitation instabilities such as rotating cavitation and cavitation surge. Until now, these cavitation instabilities were reported by many researchers since the super-synchronous shaft vibration and blade stress fluctuation caused by these cavitation instabilities are serious problems for the rocket engine turbopump (Kamijo et al., 1977; de Bernarldi et al., 1993; Tsujimoto et al., 1997; Bordelon et al., 1995; Arnone et al., 2001; Joussellin et al., 2001; Azuma et al., 2001).

Until now, the propagation speed ratio of conventional rotating cavitation observed until now is approximately 1.1-1.5. However, Watanabe et al. (1999) and Horiguchi et al. (2000)

Received 25 June 2002; accepted 1 July 2002.

Address correspondence to Akira Fujii, Division of Mechanical Science, Engineering Science, Osaka University, 1-3 Machikaneyama, Toyonaka, Osaka, 560-8531, Japan. E-mail: a-fujii@me.es.osakau.ac.jp theoretically predicted the higher order rotating cavitation which has higher propagation speed ratio (about 3-6). In the present study, the higher order rotating cavitation with a propagation speed ratio of about 5 is reported. It was observed under the experiment with modified inlet casing of the inducer.

This higher order rotating cavitation has very high propagation speed compared with that of the conventional one. It is necessary to clarify the characteristics and the method of suppression about this rotating cavitation for the design of reliable inducer. In the present study, the characteristics of higher order rotating cavitation was clarified through the measurements of casing wall pressure fluctuations and the blade stress fluctuations. On the other hand, Kamijo et al. (1993) succeeded in suppressing the conventional rotating cavitation by a modification of the inlet casing. The same method was applied to suppress the higher order rotating cavitation.

\section{EXPERIMENTAL APPARATUS AND PROCEDURE}

\section{Experimental Apparatus}

Figure 1 shows the cavitation tunnel used in the present study. This tunnel is a closed loop tunnel, and the base pressure, and hence cavitation number, was adjusted by using a vacuum pump connected to the top of the pressure control tank. Tap water was used as a working fluid after degassing. The main shaft of the inducer was driven by a inverter motor with a cogged belt. A slip ring was installed at the end of the main shaft to take out the signal from strain gauges on inducer blades. The rotational speed is $3000 \mathrm{rpm}$ (i.e., rotational frequency $\mathrm{f}_{\mathrm{n}}=50 \mathrm{~Hz}$ ) throughout the present study.

\section{Test Inducer}

In Figure 2 and Table 1, the sketch and principal dimensions of the test inducer are shown respectively. The basic design of 


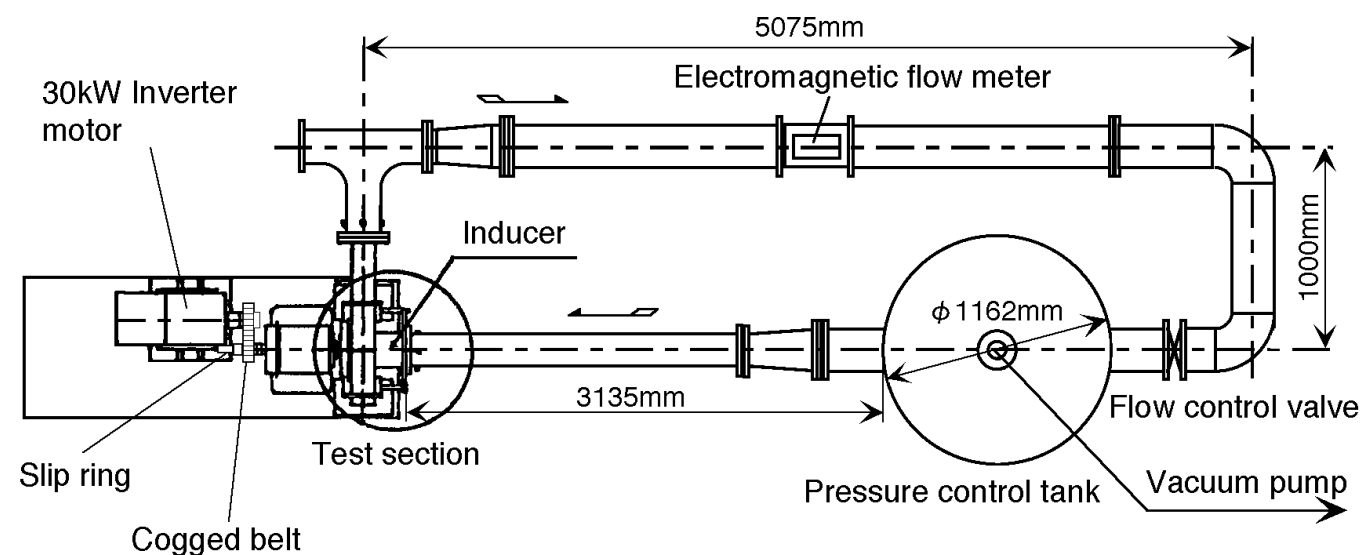

(a) Top view

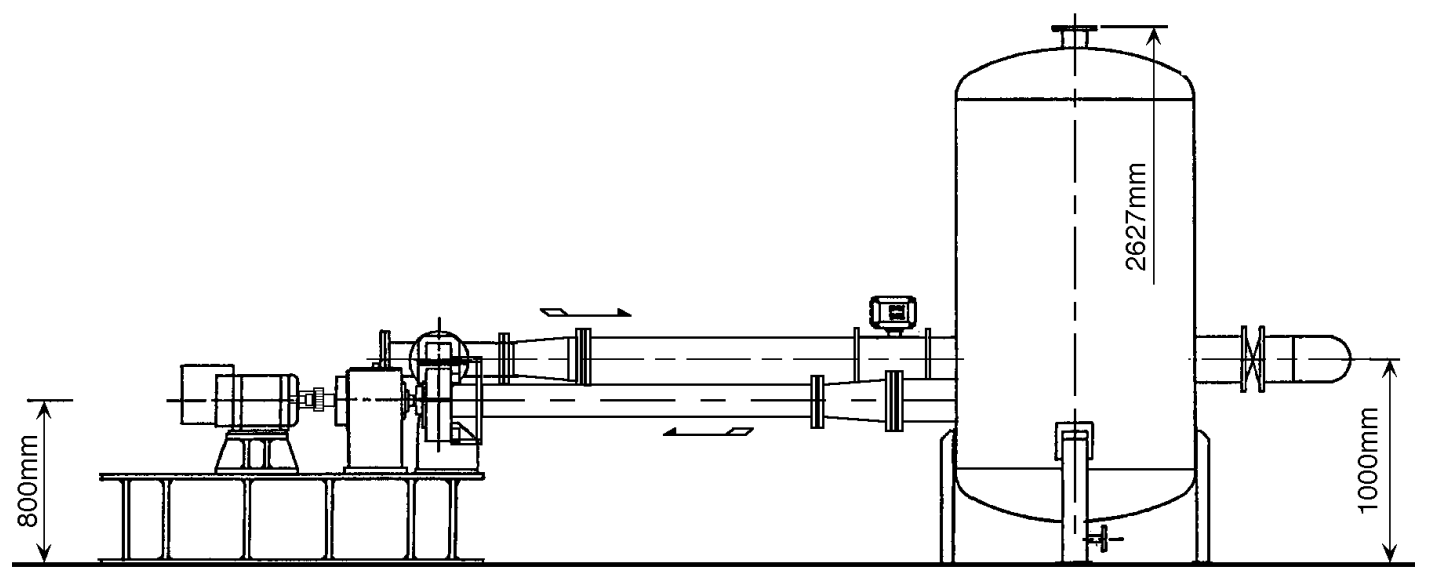

\section{(b) Side view}

FIGURE 1

Test facility. (a) Top view. (b) Side view.

this inducer is similar to the LE-7 OTP inducer. The inducer has three helical blades with a $95.5^{\circ}$ sweep-back leading edge, and its tip diameter is $149.8 \mathrm{~mm}$. The inlet blade angle is $7.5^{\circ}$ and the outlet blade angle is $9.0^{\circ}$ at the tip. The distribution of blade

TABLE 1

Principal dimensions of the test inducer (Casing A, B)

\begin{tabular}{lc}
\hline Number of blades & 3 \\
Tip diameter, $\mathrm{D}(\mathrm{mm})$ & 149.8 \\
Inlet tip blade angle, $\beta_{\mathrm{t} 1}$ & $7.5^{\circ}$ \\
Outlet tip blade angle, $\beta_{\mathrm{t} 2}$ & $9.0^{\circ}$ \\
Hub/tip ratio at inlet & 0.25 \\
Hub/tip ratio at outlet & 0.51 \\
Solidity at tip & 1.91 \\
Radial tip clearance $(\mathrm{mm})$ & 0.80 \\
Design flow coefficient, $\phi_{\mathrm{d}}$ & 0.078 \\
\hline
\end{tabular}

angle $\beta(\mathrm{r})$ is satisfied with the helical condition as $\mathrm{r} \times \tan \beta(\mathrm{r})=$ $\mathrm{R} \times \tan \beta_{\mathrm{t}}$. Design flow coefficient is $\phi_{\mathrm{d}}=0.078$.

\section{Procedure of the Experiment}

Figure 3 shows the details of the test section, the locations of the pressure sensors on the casing wall, and the locations of the strain gauges on the inducer blades. Four pressure sensors with the resonance frequency $34 \mathrm{kHz}$ were flush mounted on the casing wall at $27.5 \mathrm{~mm}$ upstream of the inducer inlet with angular distance of $90^{\circ}$. One pressure sensor was installed at the casing wall of the inducer outlet. Blade stresses were measured by using the strain gauges installed at the root near the leading edge on the pressure side of the blades.

Figure 4 shows the geometries of the inlet casing used in the present study. With Casing 0 , the radial tip clearance is $0.5 \mathrm{~mm}$ and the diameter of the casing is constant. On the other hand, 

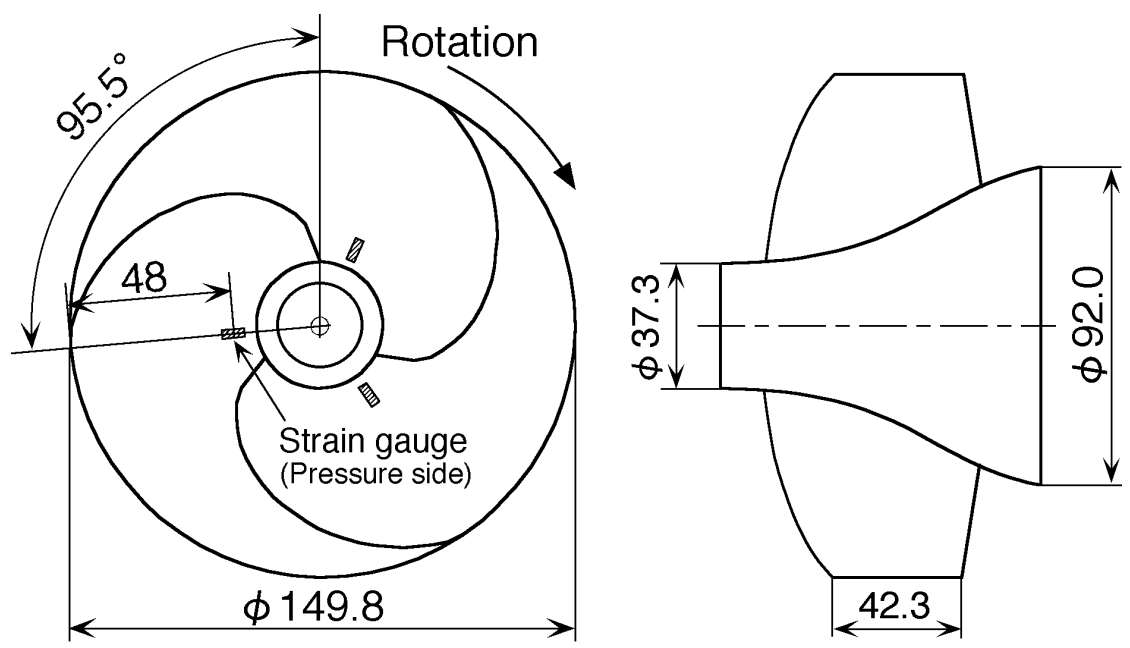

FIGURE 2

Sketch of test inducer.

the radial tip clearance is $0.8 \mathrm{~mm}$ with Casing A and Casing B. In addition, Casing $\mathrm{A}$ has a $0.8 \mathrm{~mm}$ step at the leading edge, and Casing B has a $1.8 \mathrm{~mm}$ step at the $5 \mathrm{~mm}$ downstream of the leading edge. In these two casings, the upstream diameter of the casing is larger than that at the inducer.

Static pressure performances with these casings are shown in Figure 5. Near the design flow rate $\left(\phi_{\mathrm{d}}=0.078\right)$, the static pressure coefficient with Casing $\mathrm{A}$ is smaller than that of Casing 0 because of the wider tip clearance. Casing B has the lowest pressure performance. These casings are made of transparent plastic to observe the cavity on the inducer blade by stroboscopic light.

\section{EXPERIMENTAL RESULTS}

The results of experiment with Casing 0 were reported by Tsujimoto et al. (1997) and Azuma et al. (2001). These reports presented that the various cavitation instabilities such as rotating cavitation, asymmetric cavitation, and cavitation surge occur at design flow rate.

In the following section, the experimental result with Casing $\mathrm{A}$, with which the higher order rotating cavitation has been observed, will be presented.

\section{Cavitation Performance, Cavity Length, and Mean Blade Stress}

Figure 6 shows the static pressure coefficient $\left(\psi_{\mathrm{s}}\right)$, cavity length at the tip $(1 / \mathrm{h})$, and the time averaged blade stress $\left(\sigma_{\mathrm{m}}\right)$ versus cavitation number $(\sigma)$. The occurrence region of conventional rotating cavitation, higher order rotating cavitation, and cavitation surge are also shown in the figure.

The static pressure coefficient does not decrease even with the occurrence of cavitation instabilities. The conventional rotating

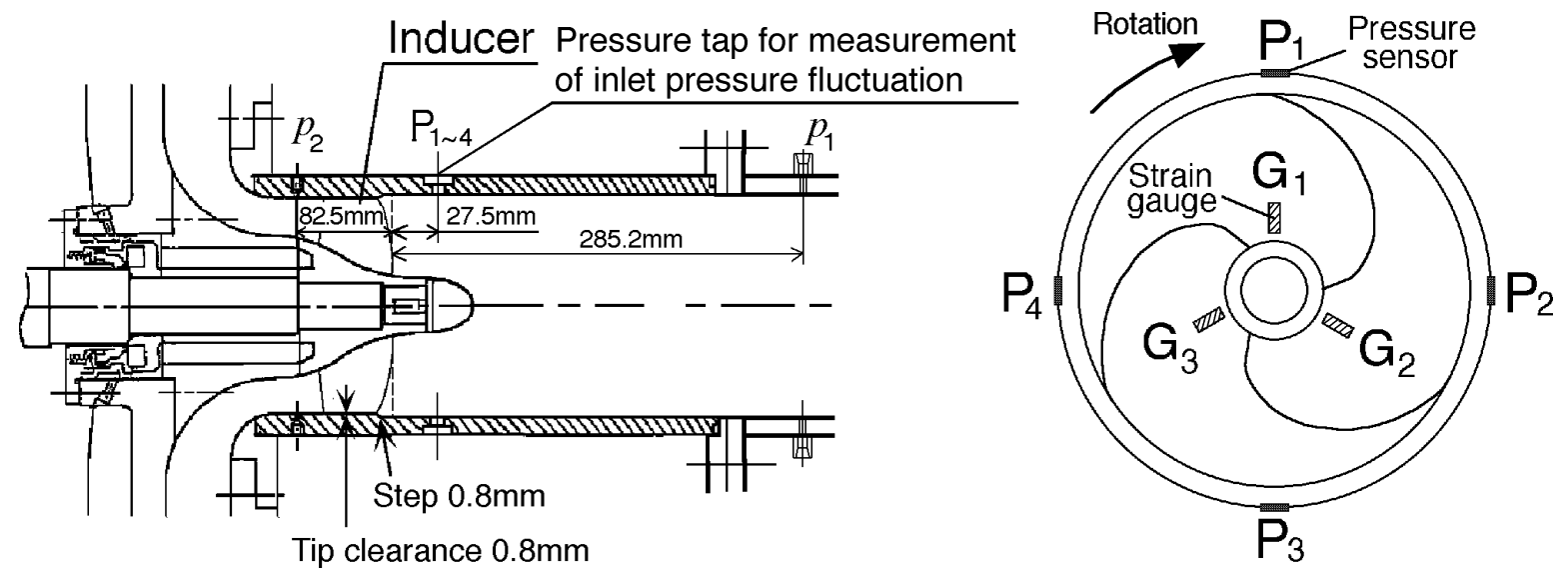

FIGURE 3

Inducer cross section showing the locations of pressure sensors and strain gauges. 


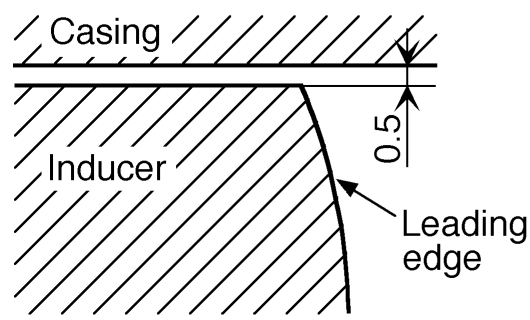

(a) Casing 0

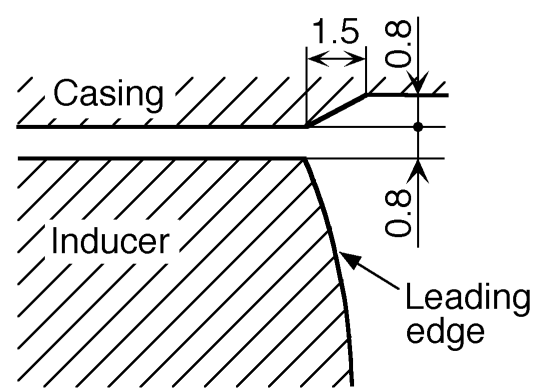

(b) Casing A

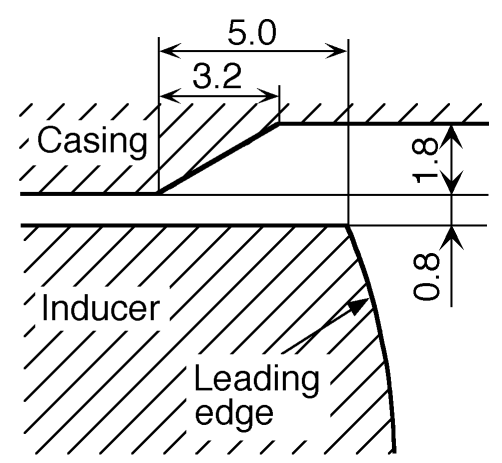

(c) Casing B

\section{Units in $\mathrm{mm}$}

FIGURE 4

Geometries of inlet casing. (a) Casing 0. (b) Casing A. (c) Casing B.

cavitation starts to occur when the cavity length develops over $70 \%$ of the spacing, in the same as with Casing 0 (Azuma et al., 2001). However, higher-order rotating cavitation and higher order cavitation surge are observed with Casing A, at a relatively higher cavitation number i.e., with shorter cavity length less than $70 \%$ of the spacing. The mean blade stress at the leading edge decreases with the decreasing of the cavitation number. This is explained as follows. For the inducer with a relatively large angle of attack, the pressure difference between pressure

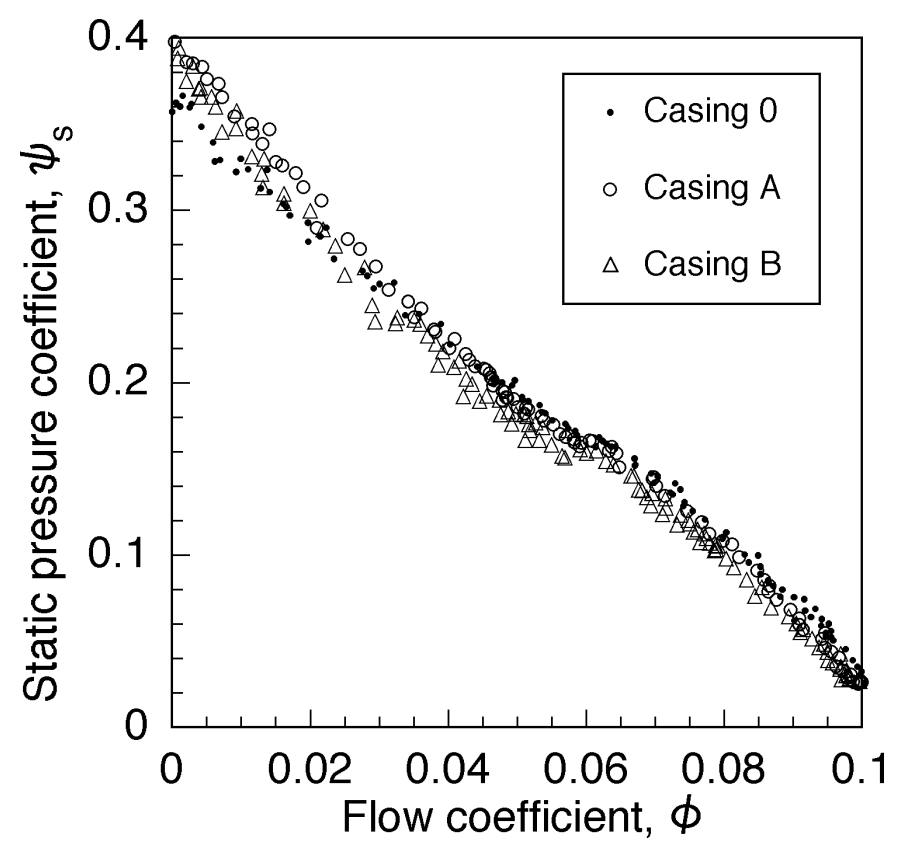

FIGURE 5

Static pressure performances with Casing A and Casing B compared with Casing 0 in non-cavitating flow. side and suction side is larger at high cavitation number. However, the pressure difference decreases with the development of the cavity since the pressure of the suction side becomes vapor pressure. This is the reason for the decrease of the blade stress near the leading edge with the decrease of cavitation number.

\section{Classification of Various Cavitation Instabilities}

Figures $7 \mathrm{a}$ and $\mathrm{b}$ show the cascade plot of the spectrum of the inlet and outlet pressure fluctuations, respectively, and Figure 7c shows that of blade stress fluctuation for various cavitation numbers. In these figures, three types of oscillations (1)-(3) ) are observed. Figure 8 shows the phase differences of inlet pressure fluctuations and blade stress fluctuations measured at various circumferential locations.

a. Conventional rotating cavitation (1)

In Figure 7, the components with $1.2 \times \mathrm{f}_{\mathrm{n}}(=61 \mathrm{~Hz})$ in inlet pressure fluctuation and with $(1.2-1.0) \times \mathrm{f}_{\mathrm{n}}=0.2 \times$ $\mathrm{f}_{\mathrm{n}}(=11 \mathrm{~Hz})$ in blade stress fluctuation can be observed in the range of $\sigma=0.04-0.06$. The phase difference of inlet pressure fluctuations and blade stress fluctuations of these components are equal to the angular separations of the measurement points. Therefore, it is found that this oscillation is caused by the rotating cavitation with one cell. The propagation velocity ratio is 1.2 .

b. Higher order cavitation surge (2)

In Figure 7, the component with $244 \mathrm{~Hz}$ in both inlet pressure fluctuation and blade stress fluctuation can be observed in the range of $\sigma=0.058-0.068$. The phase difference of inlet pressure fluctuations and blade stress fluctuations measured at various circumferential locations are almost zero as shown in Figure 8. Therefore, it is found that this instability is a surge mode oscillation. The frequency of this surge mode oscillation is very high (about $5 \times \mathrm{f}_{\mathrm{n}}$ ) compared with 


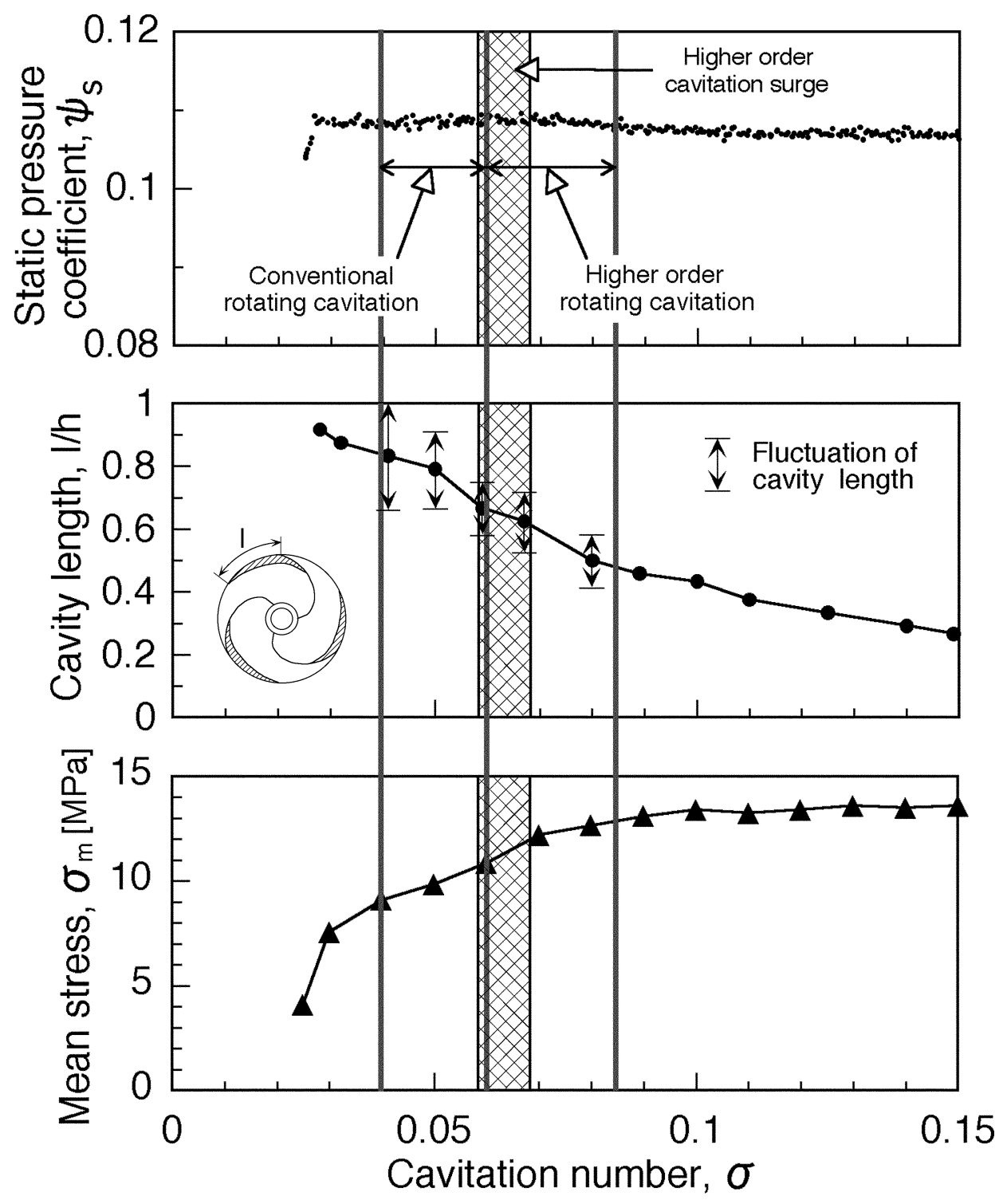

FIGURE 6

Static pressure coefficient $\left(\psi_{\mathrm{s}}\right)$, cavity length $(1 / \mathrm{h})$, and mean blade stress $\left(\sigma_{\mathrm{m}}\right)$ versus cavitation number $(\sigma)$ for $\phi=0.080$ with Casing A.

that of the conventional cavitation surge $\left(0.1-0.3 \times \mathrm{f}_{\mathrm{n}}\right)$ in the cavitation tunnel used in the present study. On account of this reason, it is called higher order cavitation surge (Tsujimoto et al., 2001).

c. Higher order rotating cavitation (3)

In Figure 7, the component with $5 \times \mathrm{f}_{\mathrm{n}}$ in the inlet/outlet pressure fluctuations and that with $(5-1) \times f_{n}=4 \times f_{n}$ in the blade stress fluctuation can be observed in the range of $\sigma=0.060-0.084$. From Figure 8 it is found that the pressure pattern rotates in the same direction of the impeller, and the number of cell is one. Propagation speed ratio of this rotating cavitation is higher (about 5) than that of conventional rotating cavitation (about 1.1-1.5). In addition, this rotating cavitation starts to occur at higher cavitation number with smaller cavity length. Therefore, this instability can be considered as a higher order rotating cavitation.

Figure 9 shows the smallest/largest cavities on the same blade under the conventional and higher order rotating cavitation. From these figures, it is found that the cavity size fluctuation of the higher order rotating cavitation is smaller than that of conventional rotating cavitation. Although the cavity fluctuates mainly along the chord under the conventional rotating cavitation, the cavity oscillates not only in the direction of the chord 


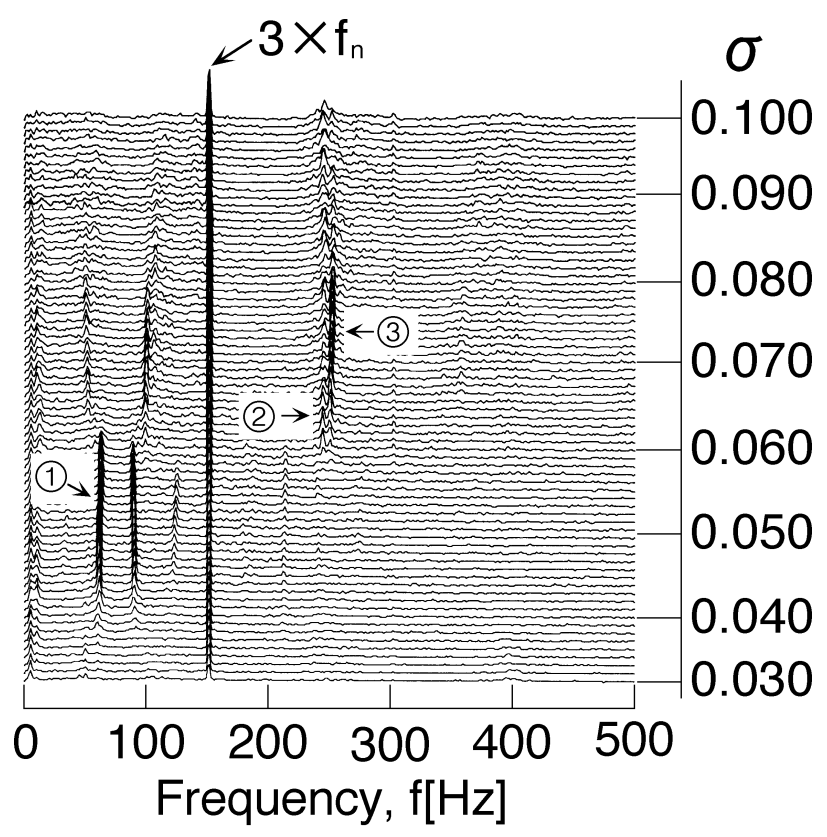

(a) Inlet pressure fluctuation

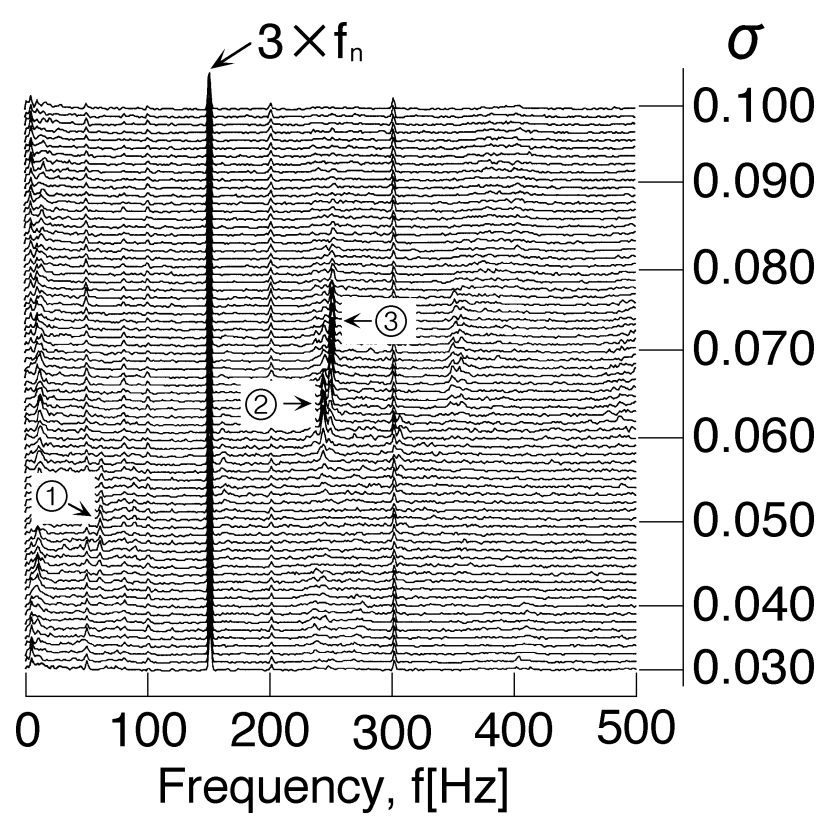

(b) Outlet pressure fluctuation

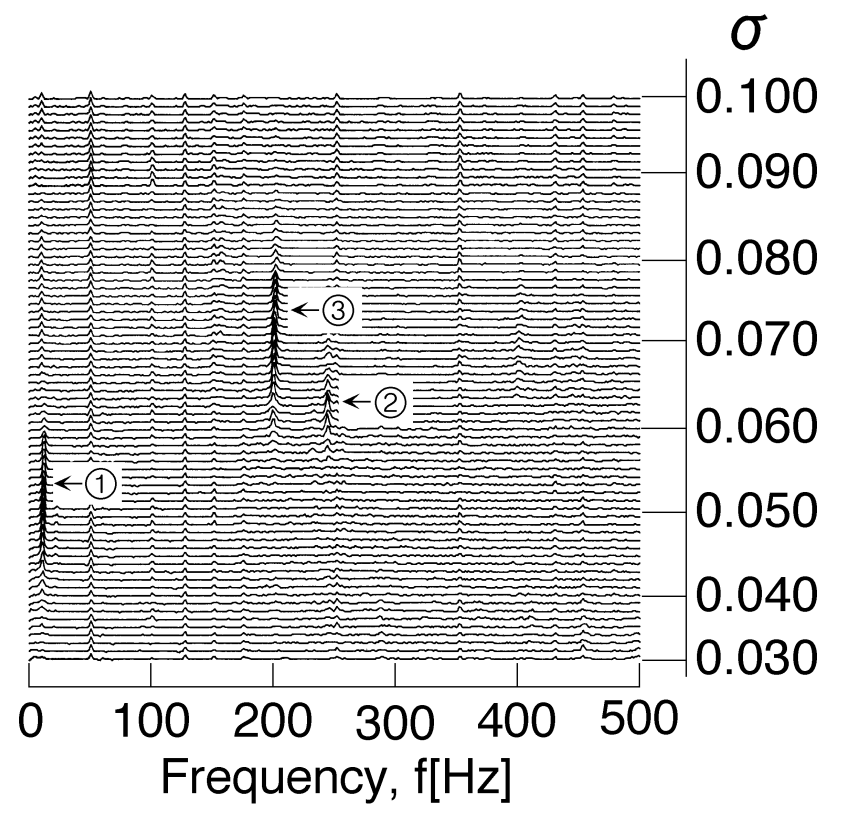

(c) Blade stress fluctuation

FIGURE 7

Spectra of inlet and outlet pressure fluctuations and blade stress fluctuation for $\phi=0.080$ with Casing A.

but also in the direction normal to the blade surface under the higher order rotating cavitation.

\section{Pressure Fluctuation Characteristics of Each Instability}

Figures 10a and $\mathrm{b}$ show the amplitude of inlet and outlet pressure fluctuations caused by cavitation instabilities. The ampli- tude of pressure fluctuation at the outlet caused by conventional rotating cavitation is significantly smaller than that at the inlet (Kamijo et al., 1977). To the contrary, the outlet pressure fluctuation caused by the higher order rotating cavitation is larger than that at the inlet. The level of inlet and outlet pressure fluctuations caused by higher order cavitation surge is almost the same. 


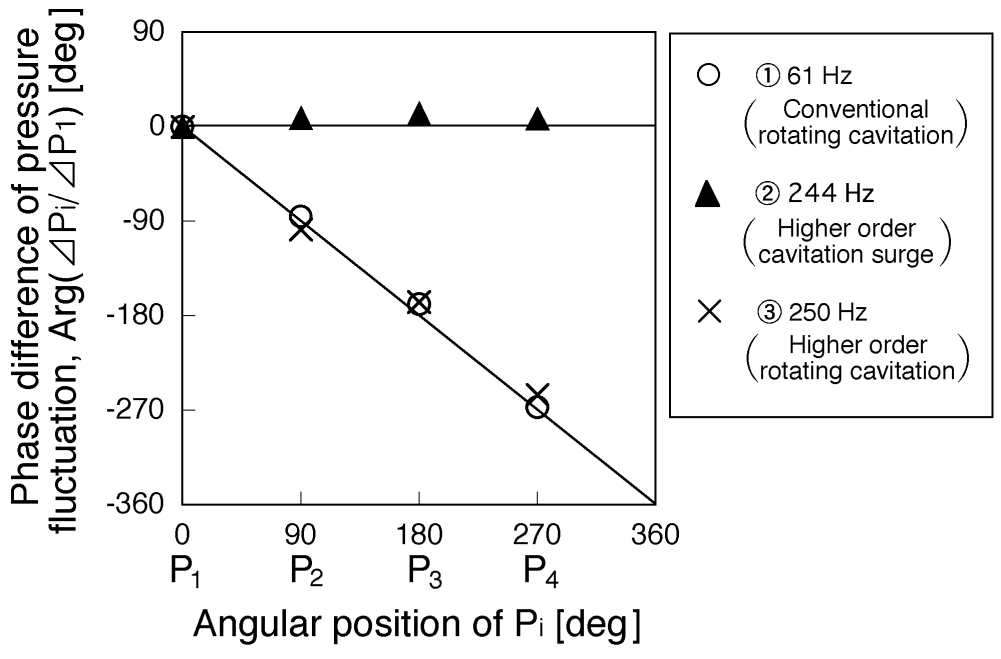

(a) Inlet pressure fluctuation
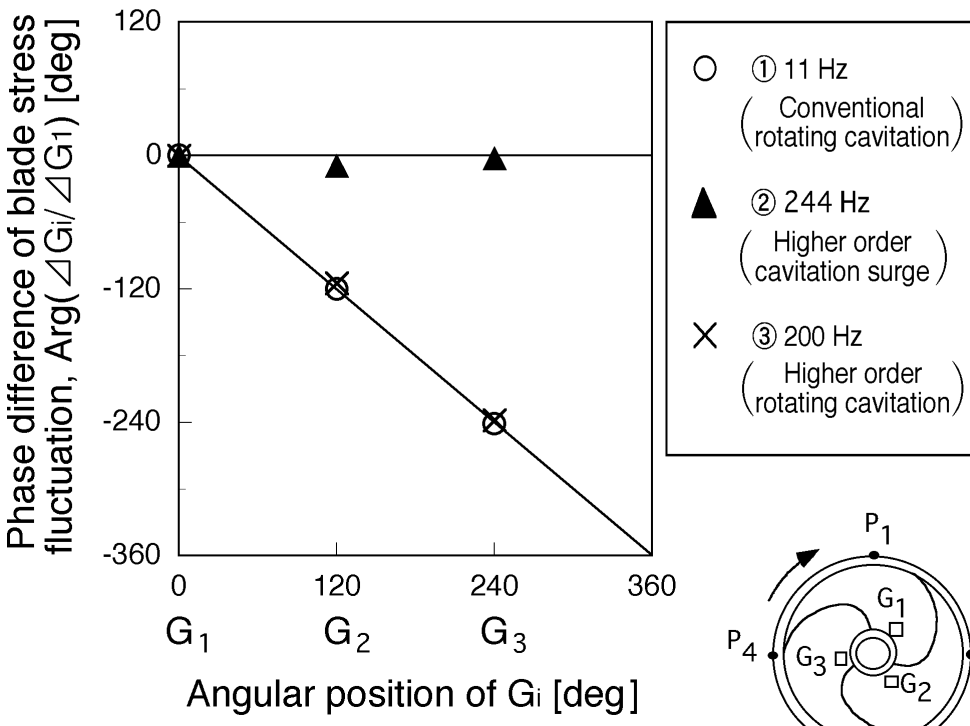

A (2) $244 \mathrm{~Hz}$ (Higher order (cavitation surge)

$X$ (3) $200 \mathrm{~Hz}$ ( $\left.\begin{array}{c}\text { Higher order } \\ \text { rotating cavitation }\end{array}\right)$

(b) Blade stress fluctuation

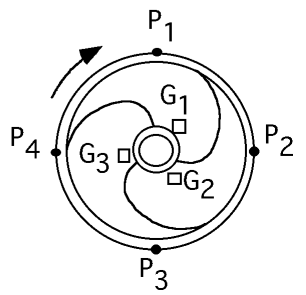

FIGURE 8

Phase difference of inlet pressure fluctuations and blade stress fluctuations caused by unsteady cavitaion measured at various circumferential locations for $\phi=0.080$ with Casing A.

Figure 10c shows the amplitude of blade stress fluctuations caused by the cavitation instabilities. The difference of the amplitude among three blades is not so large. For each cavitation instability, the cavitation number at which the amplitude of blade stress fluctuations becomes maximum is almost the same as that of pressure fluctuations. The maximum value of the stress fluctuations is about $20 \%$ of the mean blade stress under noncavitating condition.

\section{Effects of Flow Rate}

Figure 11 shows the amplitude of blade stress fluctuations caused by cavitation instabilities at various flow rates. The higher order rotating cavitation and higher order cavitation surge occur at higher flow rate than the design flow rate. As we decrease the flow rate, these instabilities start to occur at higher cavitation number, as predicted by the analysis (Watanabe et al., 1999; Horiguchi et al., 2000). 


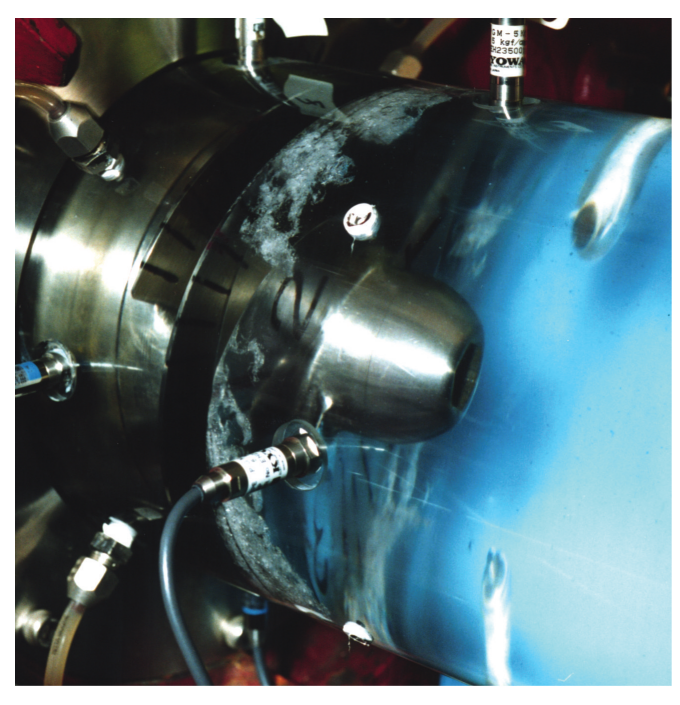

Smallest cavity

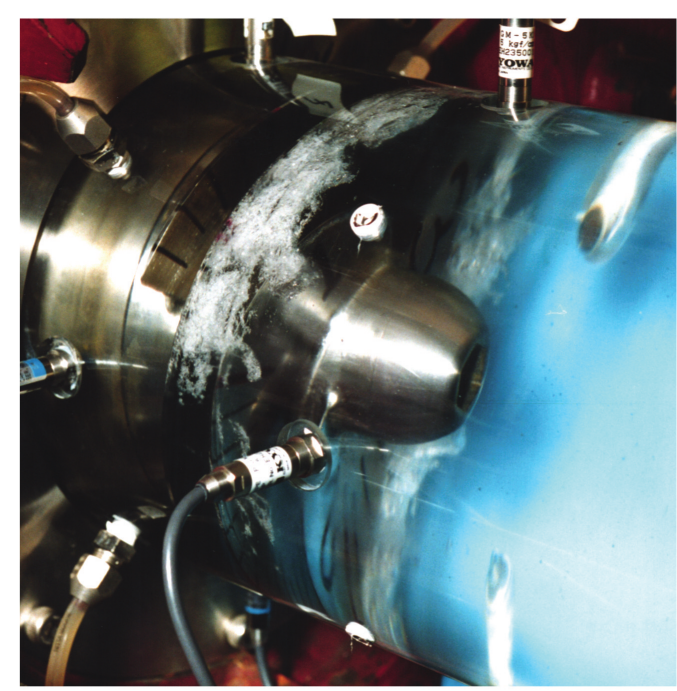

Largest cavity

\title{
(a) Conventional rotating cavitation
}

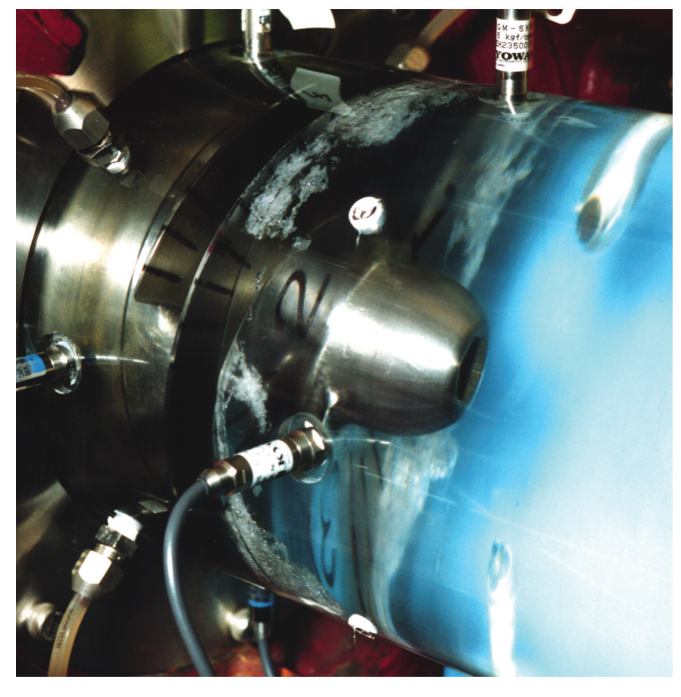

Smallest cavity

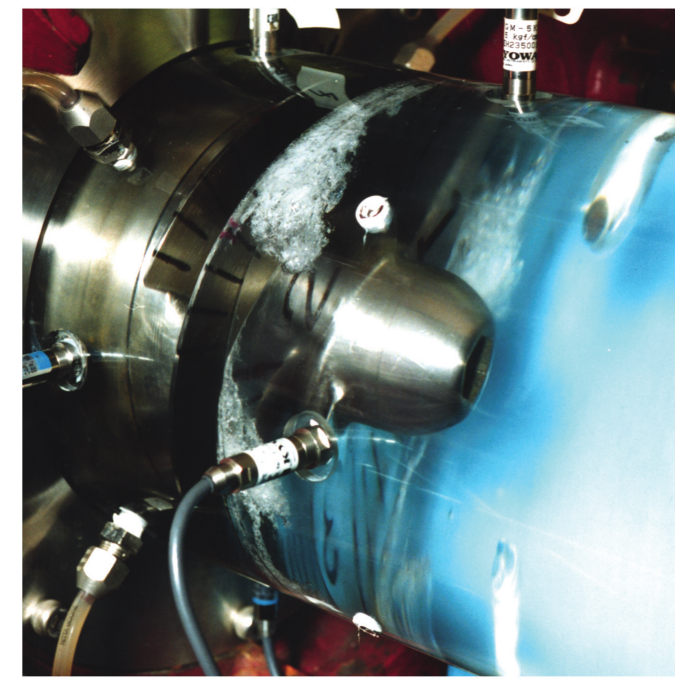

Largest cavity

\section{(b) Higher order rotating cavitation}

\author{
FIGURE 9
}

Photographs comparing cavity fluctuation between conventional and higher order rotating cavitation. (a) Conventional rotating cavitation. (b) Higher order rotating cavitation. 


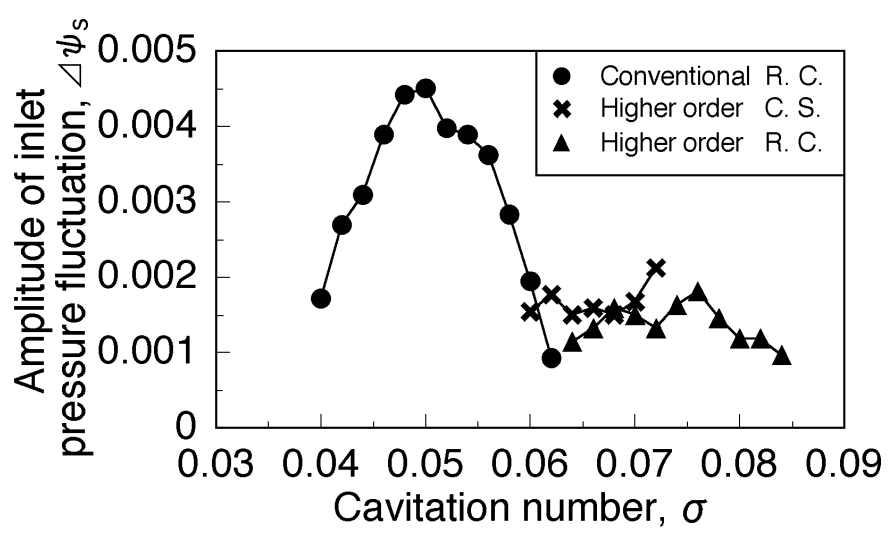

(a) Inlet pressure fluctuation

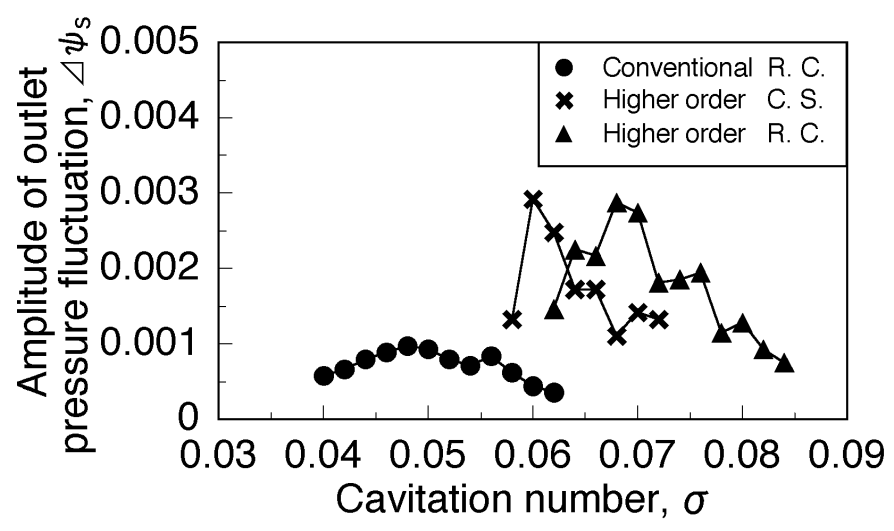

(b) Outlet pressure fluctuation

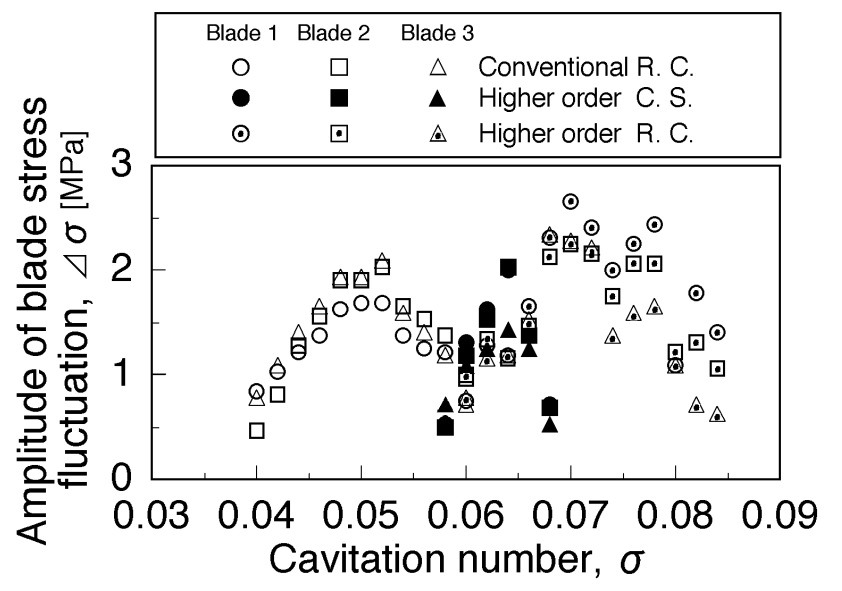

\section{(c) Blade stress fluctuation}

FIGURE 10

Amplitude of inlet and outlet pressure fluctuations and blade stress fluctuations caused by unsteady cavitation for $\phi=0.080$ with Casing A.
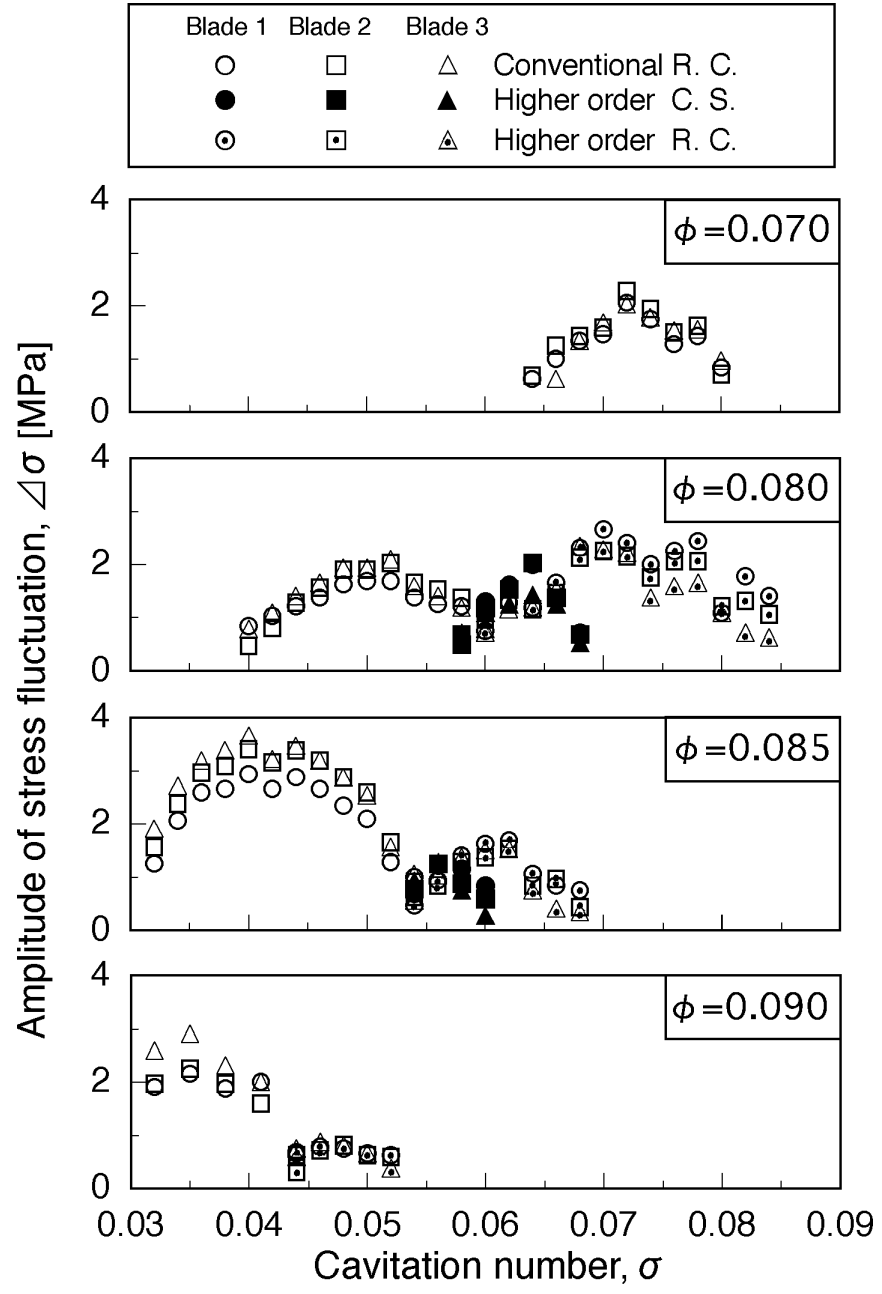

FIGURE 11

Amplitude of stress fluctuation caused by unsteady cavitation for various flow rates with Casing A.

\section{COMPARISON BETWEEN EXPERIMENTAL RESULT AND THEORETICAL ANALYSIS}

The higher order rotating cavitation and cavitation surge observed in the present study have been predicted by the analysis using the 2-D singularity method (Watanabe et al., 1999; Horiguchi et al., 2000). Calculations were carried out by using the method to compare with the experimental result. The geometry of the cascade is set to $\mathrm{C} / \mathrm{h}=1.91, \beta=9.0^{\circ}$ which are the values at the blade tip in the experiment. Figure 12 compares the propagation speed ratio of rotating cavitations and the frequency ratio of the surge mode oscillations with the present experimental results based on the steady cavity length. In the experiment, the higher order rotating cavitation starts to occur near the predicted onset point. In addition, propagation speed ratio is reasonably predicted. However, the onset point of higher order surge mode oscillation does not agree, although the frequency is predicted reasonably. Conventional cavitation surge can be observed around $10 \mathrm{~Hz}\left(f=0.2 \times f_{n}\right)$ in Figures $7 a$ and $b$. 


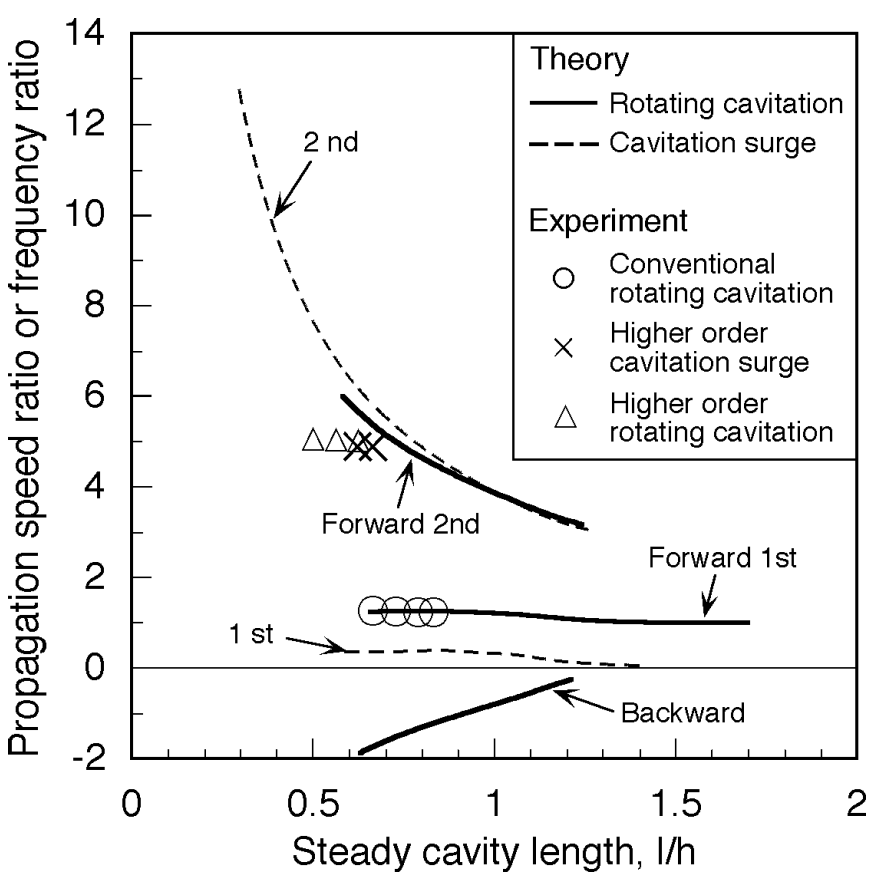

FIGURE 12

Comparison between the experimental values and calculated values for the propagation speed ratio of rotating cavitation and frequency ratio of cavitation surge for $\phi=0.080$ with Casing A.

However, the amplitude is very small and it cannot be identified in the blade stress fluctuation (see Figure 7c). Backward rotating cavitation was not observed throughout the present study.

\section{SUPPRESSION OF CAVITATION INSTABILITIES}

Kamijo et al. (1993) found that the conventional rotating cavitation can be suppressed by the modification of the casing. The step at the inlet of Casing A was intended to suppress the conventional rotating cavitation, but it was not effective enough. To enhance the stabilizing effect, Casing B with larger step was designed and tested. Figure 13 shows the cascade plot of the spectrum of the inlet pressure fluctuation for $\phi=0.080$ with Casing B. It is found that the higher order rotating cavitation and higher order cavitation surge were suppressed by using Casing $\mathrm{B}$ in addition to the conventional rotating cavitation. The asymmetric cavitation was observed at low cavitation number with Casing 0 in the previous experiments (Tsujimoto et al., 1997; Azuma et al., 2000). This was also suppressed by using Casing A and Casing B. It was confirmed that all cavitation instabilities disappear within the range of flow coefficient $\phi=0.070-0.090$ with Casing B. However, we note here that the application of Casing B causes the deterioration of the pressure performance, as shown in Figure 5.

In Figure 13, broadband component can be observed at the smaller frequency than the blade passing frequency $\left(=3 \times \mathrm{f}_{\mathrm{n}}\right)$. This is also observed at a higher cavitation number (almost non-

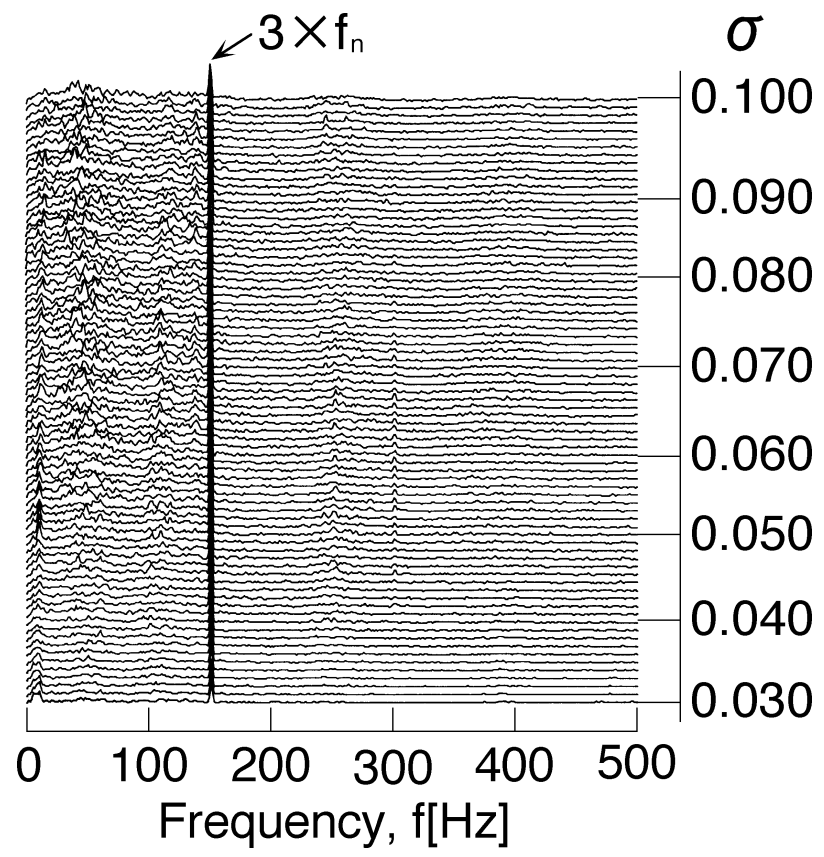

FIGURE 13

Spectrum of inlet pressure fluctuation for $\phi=0.080$ with Casing B.

cavitation). Therefore, it seems that these components are caused by the back flow vortex at the inlet.

\section{CONCLUSIONS}

A higher order rotating cavitation, which has been predicted by a stability analysis, was observed in the experiment with modified inlet casing. The following characteristics were found through the measurements of pressure fluctuations and blade stress fluctuations.

(1) Higher order rotating cavitation occurs at higher cavitation number compared with conventional rotating cavitation. It has one cell and rotates in the same direction of impeller rotation. Its propagation speed ratio is about 5 .

(2) The maximum value of blade stress fluctuations caused by the higher order rotating cavitation is about $20 \%$ of the mean stress under non-cavitating condition.

(3) The outlet pressure fluctuations caused by the conventional rotating cavitation is significantly smaller than that at the inlet. However, the outlet pressure fluctuation caused by the higher-order rotating cavitation is larger than that at the inlet.

(4) The higher order rotating cavitation occurred at a higher flow rate than the design flow rate. The cavitation number range of higher order rotating cavitation and higher-order cavitation surge increases as we decrease the flow rate. This is similar to conventional rotating cavitation, and is predicted by the theory.

(5) All cavitation instabilities can be suppressed by properly modifying the geometry of inlet casing. 


\section{ACKNOWLEDGMENTS}

The authors would like to thank Mr. Tomoatsu Inoue of Kyowa Electronic Instruments CO., LTD. for his experimental support and advice. Mr. Shigeaki Miyata and Mr. Yusuke Kawamura's support in conducting experiments are also acknowledged. This study is supported by the Grand-in-Aid for Science Research of the Ministry of Education, Science, Sports, and Culture, and the Hatakeyama Foundation.

\section{NOMENCLATURE}

$\mathrm{D}$ inducer diameter

f frequency of pressure fluctuations or blade stress fluctuations

$f_{n} \quad$ shaft rotational frequency

$\mathrm{G}_{\mathrm{i}}$ measurement points of blade stress ( $\mathrm{i}=1-3$ )

$\mathrm{h}$ tip blade spacing

1 cavity length at the tip

$\mathrm{p}_{1}$ pressure at inlet

$\mathrm{p}_{1 \mathrm{t}}$ total pressure at inlet

$\mathrm{p}_{2}$ pressure at outlet

$\mathrm{p}_{\mathrm{v}} \quad$ vapor pressure

$\Delta \mathrm{p}$ pressure fluctuation (zero-to-peak)

$\mathrm{P}_{\mathrm{i}}$ measurement points of the pressure fluctuation ( $\left.\mathrm{i}=1-4\right)$

$\mathrm{r}$ radius

$\mathrm{R}$ blade tip radius

$\mathrm{U}_{\mathrm{t}}$ peripheral speed of inducer tip $=\pi \mathrm{Df}_{\mathrm{n}}$

$\mathrm{v}_{1}$ axial velocity at inducer inlet $=$ flow rate/inlet area

$\alpha \quad$ incidence angle, i.e., angle between the inlet relative velocity and the blade $=\beta_{\mathrm{t} 1}-\tan ^{-1} \phi$

$\beta \quad$ blade angle

$\beta_{\mathrm{t}} \quad$ tip blade angle $\left(\beta_{\mathrm{t} 1}\right.$ : inlet tip blade angle; $\beta_{\mathrm{t} 2}$ : outlet tip blade angle)

$\rho$ density

$\sigma \quad$ cavitation number $=\left(\mathrm{p}_{1}-\mathrm{p}_{\mathrm{v}}\right) /\left(\rho \mathrm{U}_{\mathrm{t}}^{2} / 2\right)$

$\sigma_{\mathrm{m}}$ mean stress of blade [MPa]

$\Delta \sigma$ blade stress fluctuation (zero-to-peak)

$\phi \quad$ flow coefficient $=\mathrm{v}_{1} / \mathrm{U}_{\mathrm{t}}$

$\phi_{\mathrm{d}} \quad$ design flow coefficient

$\psi_{\mathrm{s}} \quad$ static pressure coefficient $=\left(\mathrm{p}_{2}-\mathrm{p}_{1 \mathrm{t}}\right) /\left(\rho \mathrm{U}_{\mathrm{t}}^{2}\right)$
$\Delta \psi$ coefficient of pressure fluctuations $=\Delta \mathrm{p} /\left(\rho \mathrm{U}_{t}^{2}\right)$ (zero-topeak)

\section{REFERENCES}

Arnone, A., Boncinelli, P., Capuani, A., Spano, E., and Rebattet, C. 2001. "ARIANE 5" TPLOX inducer design strategies to enhance cavitating performance. Proceedings of 4th International Symposium on Cavitation, Session B7. 004, Pasadena, California.

Azuma, S., Yoshida, Y., and Tsujimoto, Y. 2001. Unsteady blade stress due to rotating cavitation in an inducer. Turbomachinery (in Japanese) 29(3):147-154.

de Bernaldi, J., Joussellin, F., and Von Kaenel, A. 1993. Experimental analysis of instabilities related to cavitation in a turbopump inducer. The 1st International Symposium Pump Noise Vibration, 19.

Bordelon, Jr., W. J., Gaddis, S. W., and Nesman, T. E. 1995. Cavitation enviromental of the alternate high pressure oxygen turbopump inducer. ASME FED-Vol. 210, 39-46.

Horiguchi, H., Watanebe, S., and Tsujimoto, Y. 2000. A linear stability analysis of cavitation in a finite blade count impeller. ASME Journal of Fluids Engineering 122(4):798-805.

Joussellin, F., Courtot, Y., Coutier-Delgosha, O., and Reboud, J. L. 2001. Cavitating inducer instabilities: Experimental analysis and 2D numerical simulation of unsteady flow in blade cascade. Proceedings of 4th International Symposium on Cavitation, Session B8. 002, Pasadena, California.

Kamijo, K., Shimura, T., and Watanabe, M. 1977. An experimental investigation of cavitating inducer instability. ASME Paper 77-WA/FE14

Kamijo, K., Yoshida, M., and Tsujimoto, Y. 1993. Hydraulic and mechanical performance of LE-7 LOX pump inducer. AIAA Journal of Propulsion and Power 9(6):819-826.

Tsujimoto, Y., Yoshida, Y., Maekawa, Y., Watanabe, S., and Hashimoto, T. 1997. Observations of oscillating cavitations of an inducer. ASME Journal of Fluids Engineering 119(4):775-781.

Tsujimoto, Y. 2001. Simple rules for cavitation instabilities in turbomachinery. Proceedings of 4th International Symposium on Cavitation, Lecture 006, Pasadena, California.

Watanabe, S., Sato, K., Tsujimoto, Y., and Kamijo, K. 1999. Analysis of rotating cavitation in a finite pitch cascade using a closed cavity model and a singularity method. ASME Journal of Fluids Engineering 121:834-840. 

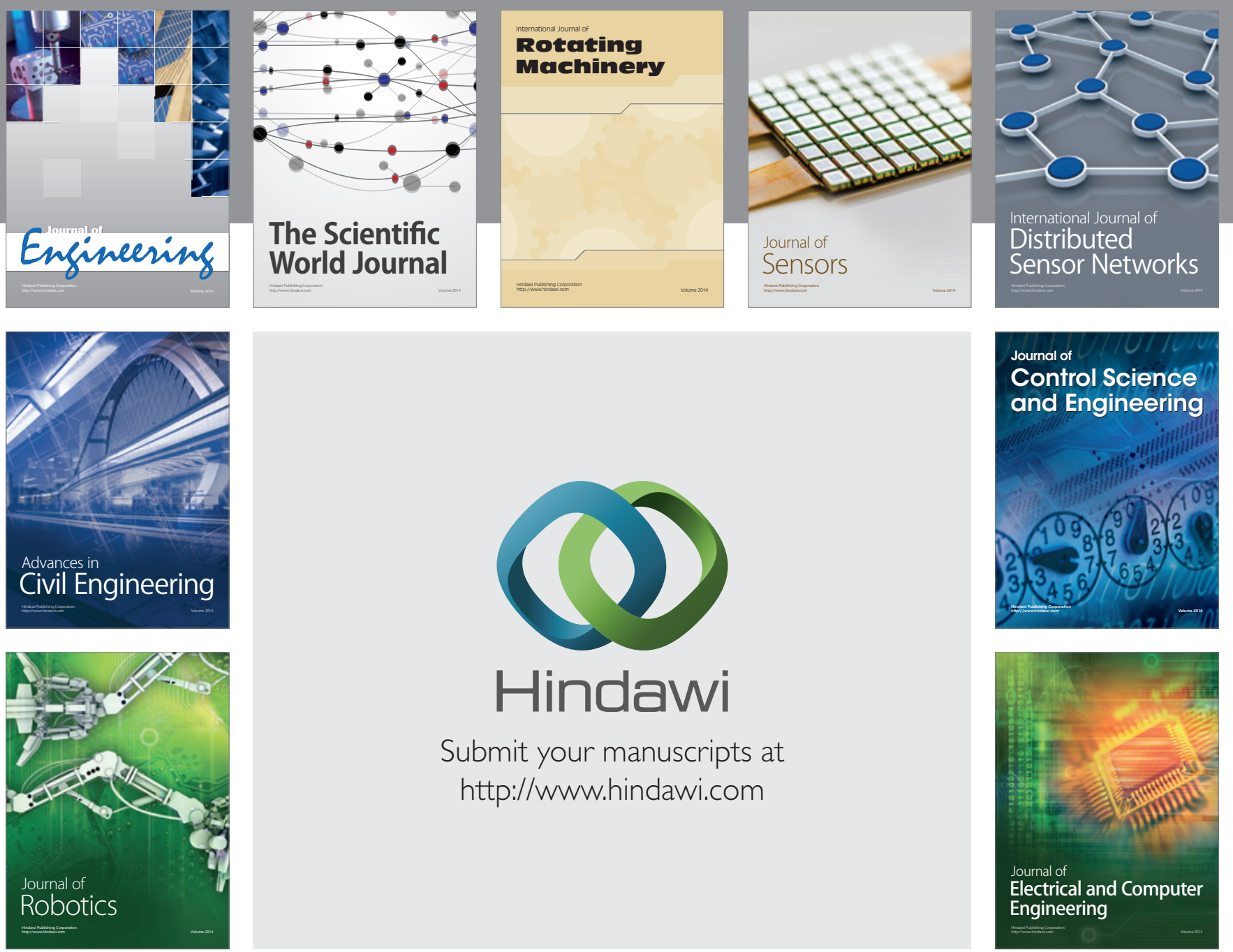

Submit your manuscripts at

http://www.hindawi.com
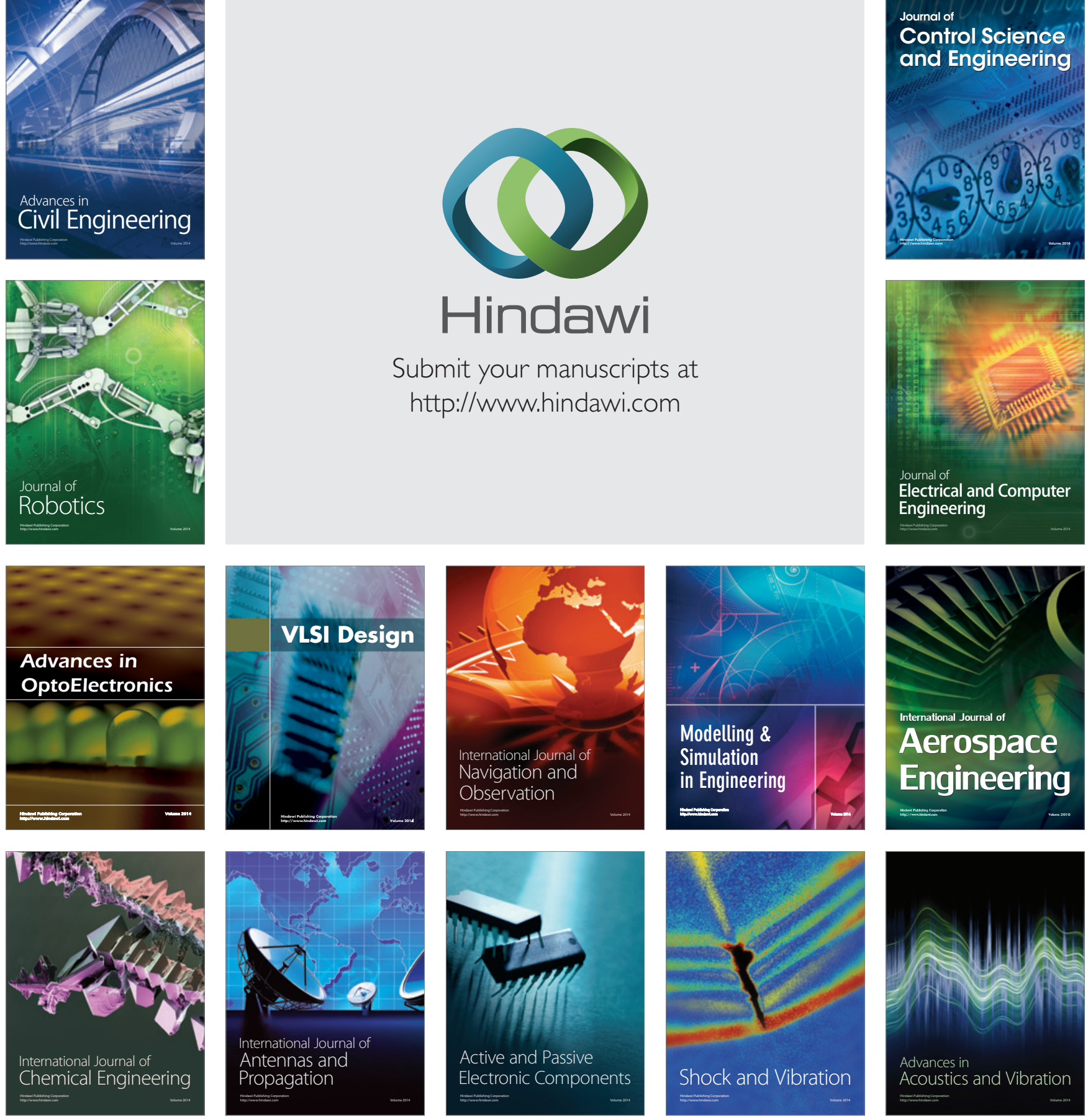